\title{
POLÍTICA NACIONAL DOS RESÍDUOS SÓLIDOS: ABORDAGEM DA PROBLEMÁTICA NO BRASIL E A SITUAÇÃO NA REGIÃO SUL
}

\author{
Laís Lavnitcki1 \\ Camila AngelicaBaum2 \\ Valter AntonioBecegato3
}

\begin{abstract}
RESUMO
Foram 20 anos de tramitações, para a criação da Lei 12.305/2010 que institui a Política Nacional dos Resíduos Sólidos, que conta com objetivos para enfrentamento dos principais problemas ambientais, sociais e econômicos. Partindo desse pressuposto, este trabalho tem como objetivo analisar 0 desenvolvimento e alcance das metas e objetivos propostos pela Política Nacional dos Resíduos Sólidos através da análise de dados obtidos em documentos e periódicos online. Verificou-se que muitos municípios não elaboraram o Plano de Resíduos Sólidos que dá subsídios e contribuí para uma gestão adequada. Assim, mesmo após cinco anos da publicação da Política Nacional de Resíduos Sólidos o Brasil apresentou uma melhora de $2 \%$ no volume de resíduos sólidos destinados adequadamente enquanto a região sul apresentou 10,5\%. Os índices de geração aumentam a cada ano o que é acompanhado por índices bem inferiores de reciclagem, reutilização, logística reversa e destinação, sendo difícil afirmar os dados devido aos serviços informais e inconsistência dos dados. Porém, verifica-se que a situação está bastante distante do que foi discutido e registrado na Lei 12.305/2010.
\end{abstract}

Palavras-chave: Disposição Inadequada; Plano de Resíduos Sólidos; Geração; Reciclagem.

\footnotetext{
${ }^{1}$ Formada em Engenharia Ambiental e Sanitária pela Universidade Federal de Santa Maria campus Frederico Westphalen-RS e Mestranda no Programa de Pós Graduação em Ciências Ambientais pela Universidade do Estado de Santa Catarina-CAV.

${ }^{2}$ Técnica em Mecânica de Usinagem (Curso Técnico, Escola de Educação Profissional SENAI Vergílio Lunardi, SENAI). Engenheira Sanitarista e Ambiental (UFSM, 2010-2015). Mestranda em Ciências Ambientais (Programa de Pós-Graduação em Ciências Ambientais, UDESC, 2016-atual).

${ }^{3}$ Doutor em Geologia Ambiental pela Universidade Federal do Paraná (2005). Atualmente é professor Associado da Universidade do Estado de Santa Catarina. Chefe de Gabinete da Reitoria da UDESC em 2012.
} 


\title{
NATIONAL SOLID WASTE POLICY: PROBLEM APPROACH IN BRAZIL AND THE SITUATION IN THE SOUTH REGION
}

\begin{abstract}
There were 20 years of procedures for the creation of Law 12.305/2010, which establishes the National Policy on Solid Waste, which has objectives to address the main environmental, social and economic problems. Based on this assumption, this work aims to analyze the development and achievement of the goals and objectives proposed by the National Solid Waste Policy through the analysis of data obtained from online documents and periodicals. It was verified that many municipalities did not elaborate the Plan of Solid Waste that gives subsidies and contributes to an adequate management. Thus, even after five years of publication of the National Solid Waste Policy, Brazil presented a $2 \%$ improvement in the volume of solid waste destined adequately while the south presented $10.5 \%$. The generation indices increase each year, which is accompanied by much lower rates of recycling, reuse, reverse logistics and destination, and it is difficult to state the data due to informal services and data inconsistency. However, it appears that the situation is far from what was discussed and recorded in Law 12.305/2010.
\end{abstract}

Keywords:InadequateDisposal; SolidWastePlan; Generation; Recycling.

\section{INTRODUÇÃO}

As atividades realizadas pelo homem para sua sobrevivência desde os primórdios já geravam resíduos que eram descartados nas mais diversas áreas, devido a sua característica nômade (ABREU \& PALHARES, 2006). A partir do momento em que o homem evoluiu e passou a fixar-se em determinados locais, teve-se o aumento da população em uma área, formandose as civilizações, que resultaram em mudanças relacionadas aos resíduos devido as alterações de hábitos (PHILIPPI, 1979).

Menciona-se de acordo com Nagashima et al. (2011) que na Idade Média os rejeitos das civilizações eram lançados em lugares distantes a céu aberto, pelo fato de provocarem mau cheiro, sujeira e doenças. Mas foi só a partir do século XVIII, devido ao ápice da Revolução Industrial e suas tecnologias, que o homem passou a consumir os mais diversos produtos, começando a se destacar os problemas ambientais relacionados aos resíduos sólidos (ABREU \& PALHARES, 2006).

Com o surgimento de produtos e materiais sintéticos associados à urbanização e consumo em grande escala, ocorreu um aumento considerável 
na produção de resíduos que eram descartados sem a devida atenção, com posição secundária nos debates, causando problemas socioambientais e proliferando-se os "lixões" durante as décadas de 1970 e 1980. Felicori et al. (2015) define lixões como áreas escolhidas aleatoriamente, sem qualquer controle quanto a poluição da água, solo e ar ao seu entorno sendo considerada uma técnica inadequada de disposição de resíduos.

Em 1985, criou-se o Prosanear (Programa de Saneamento para População de Baixa Renda), tendo-se uma visão integrada do saneamento, com ações e financiamentos voltados às quatro esferas, incluindo-se pela primeira vez os resíduos sólidos (NAGASHIMA et al., 2011). Em 1990 ocorreu o avanço do saneamento ambiental com a responsabilização dos municípios pelo gerenciamento dos resíduos produzidos em seu território. No entanto, a descentralização dos serviços não foi acompanhada pelo incentivo e distribuição de recurso, intensificando mais ainda a problemática dos resíduos sólidos no país (DEMAJOROVIC et al., 2005).

Diante disso, os resíduos sólidos tornaram-se uma grande preocupação contemporânea, tendo como agravantes a mudança nos padrões de consumo, desenvolvimento industrial e avanços tecnológicos que levaram a alterações na composição e quantidade de resíduos gerados (GÓES, 2012), sendo necessárias duas décadas de tramitações no Congresso Nacional para que se tivesse uma lei relacionada aos resíduos sólidos em nível nacional, que permitisse o avanço necessário ao país para o enfrentamento dos principais problemas ambientais, sociais e econômicos relacionados ao manejo inadequado dos resíduos sólidos (RAUBER, 2011).

De acordo com Costa (2015), em 1989, através do Projeto de Lei $n^{\circ}$ 354/89 que dispunha sobre o acondicionamento, coleta, tratamento, transporte e a destinação final dos resíduos de serviços de saúde, foi à primeira inciativa que desencadeou a elaboração da Política Nacional dos Resíduos Sólidos (PNRS), que após análise e tramitância de diversos projetos juntamente com a resistência do setor industrial quanto aos princípios da lei, acabou-se prorrogando sua aceitação, sendo aprovada pelo Congresso Nacional somente em junho de 2010.

A Lei 12.305 de 02 de agosto de 2010 institui a PNRS, regulamentada pelo Decreto 7.404 de 23 de dezembro de 2010, que estabelece algumas 
normas para sua melhor execução. A PNRS dispõe de princípios, objetivos, instrumentos e diretrizes para gestão e gerenciamento de resíduos sólidos, inclusive os classificados como perigosos, excluindo-se somente os rejeitos radioativos. A lei delega a responsabilidade dos geradores e do poder público, além de instrumentos para propiciar o consumo sustentável com práticas de reciclagem, reutilização e destinação ambientalmente adequada dos rejeitos.

O Brasil, a partir de agosto de 2010 através da PNRS integrando-se com as demais políticas nacionais, Política Nacional de Meio Ambiente (Lei 6.938/81), Política Nacional de Educação Ambiental (Lei 9.795/99) e a de Saneamento Básico (Lei 11.445/07), marcou o início de uma forte articulação institucional envolvendo os três entes federados do poder público - União, Estados e Municípios, que juntamente com o setor produtivo e a sociedade civil, busca soluções para os graves problemas causados pelos resíduos.

A PNRS apresenta metas como a eliminação de lixões e locais considerados inadequados para disposição, aumento na reciclagem, reutilização, tecnologias sustentáveis e principalmente o Plano de Resíduos Sólidos, que contempla os mais diversos tipos de resíduos gerados, alternativas de gestão e gerenciamento que deverão ser implantados, compatibilizando as ações correspondentes ao crescimento econômico.

Sabe-se hoje, que a PNRS coloca o Brasil em patamar de igualdade legal aos principais países desenvolvidos, porém, são enfrentados inúmeros problemas, referentes à falta de estrutura, fiscalização e demais questões, que fazem com que suas metas sejam prorrogadas e objetivos inalcançados. Partindo desse pressuposto, surge a importância da elaboração desse estudo, no qual tem como objetivo analisar o desenvolvimento das metas e objetivos propostos pela PNRS e se os mesmos foram alcançados no Brasil, destacando-se a região Sul.

\section{ABORDAGEM DA PROBLEMÁTICA}

\subsection{Política Nacional dos Resíduos Sólidos: objetivos e metas}

A Lei 12.305/2010 que institui a PNRS é um tema atual, de grande interesse e relevância aos municípios brasileiros, fazendo-se necessário o seu conhecimento. Esta lei dispõe de princípios, objetivos, instrumentos e diretrizes, levando à responsabilidade aos geradores e poder público para uma gestão integrada resíduos sólidos, incluindo-se resíduos classificados como 
perigosos e excluindo-se os rejeitos radioativos. Termos e definições também são explanadas para um melhor entendimento da PNRS, incluindo inovações, como: logística reversa, acordos setoriais, responsabilidade compartilhada pelo ciclo de vida dos produtos e a diferença de resíduos sólidos e rejeitos, que até então, as demais leis não relatavam.

Segundo Pereira (2011) o mérito da Lei 12.305/2010 é, antes de tudo, sua própria existência, pois se configura um marco regulatório na legislação ambiental brasileira, trazendo mecanismos como a logística reversa, planos de gestão, coleta seletiva, responsabilidade compartilhada, bem como a inclusão social e profissional dos catadores de matérias recicláveis se tornando uma lei bastante inovadora e importante frente a problemática dos resíduos sólidos.

Maia et al. (2014) cita que não obstante sua longa tramitação, a PNRS é um texto moderno e com várias inovações, elucidando diversos conceitos de grande importância para o entendimento das questões ambientais relacionadas aos resíduos sólidos. Dentro desse contexto, a PNRS reúne princípios, objetivos e instrumentos interligados com as demais leis que devem ser adotados pelo Governo Federal de forma isolada ou em conjunto com Estados, Distrito Federal, Municípios ou particulares, visando à gestão integrada e o gerenciamento ambientalmente adequado dos resíduos sólidos.

Assim como as leis devem ser interpretadas de forma harmônica, os princípios também se encontram interligados dentro da PNRS devendo ser observadas de forma sistêmica as variáveis ambientais, sociais, culturais, tecnológicas e de saúde pública para elaboração de ações aplicáveis a realidade dos resíduos sólidos. Diante disso, entram os princípios voltados à sustentabilidade, abordados através da coleta seletiva, reciclagem, logística reversa e tecnologias que permitem o aproveitamento energético dos resíduos, e que quando esgotados, devem receber uma destinação ambientalmente adequada.

Dessa forma, pode-se então, produzir e evoluir de forma ecoeficiente com a cooperação de todos, tendo cada um à responsabilidade compartilhada pelos resíduos gerados, diminuindo os impactos negativos resultantes dos resíduos e aumentando os impactos positivos relacionados ao seu valor econômico. Para Costa (2015) a PNRS abrange todos os princípios fundamentais ao tema, buscando em conjunto, a coordenação entre produção 
e consumo consciente, onde cada integrante da cadeia produtiva e os órgãos governamentais possuem funções específicas no manejo e controle adequado dos resíduos sólidos.

Um dos instrumentos citados como fundamentais para o avanço do país na questão dos resíduos sólidos, correspondem aos Planos de Resíduos Sólidos (PRS) que devem ser criados pela união, estados e municípios abrangendo todos os resíduos gerados em seu território e sua destinação ambientalmente adequada, os quais devem ser compreendidos por toda a coletividade através de ações conjuntas com divisão de responsabilidades e obrigações (MINISTÉRIO DO MEIO AMBIENTE, 2016). Os PRS, estadual e municipal, tinham prazo até 2012 para entrar em vigor, contudo não há a obrigatoriedade na sua elaboração até este prazo ou qualquer outro limite. 0 único entrave, relativo a não elaboração dos planos até o prazo estabelecido, é de que os municípios em desacordo, não terão acesso a recursos da União destinados ao gerenciamento dos resíduos, fator esse que pode ser considerado decisivo, uma vez que principalmente os municípios de pequeno porte não têm condições financeiras, políticas, estruturais e pessoas capacitadas para elaboração e construção de um plano que atenda todos os instrumentos da PNRS, fazendo com que a gestão dos resíduos sólidos não seja prioridade.

A PNRS busca de forma geral, alcançar um cenário ótimo em relação aos resíduos sólidos, atingindo seus objetivos de reduzir, reutilizar, não gerar, reciclar, tratar e destinar os resíduos sólidos, estimulando assim, padrões sustentáveis. Isso só será possível se todos os instrumentos e princípios sejam seguidos, assim como, cumprimento das proibições e metas.

De acordo com as proibições trazidas pela PNRS, fica proibida a disposição dos resíduos a céu aberto, estando a técnica de lixões, aterros controlados e vazadouros a céu aberto como formas ilegais de disposição. Oliveira (2013) define a técnica de lixões, como uma simples descarga de resíduos no solo de forma desordenada, a céu aberto, sem controle das diferentes classes, sem compactação ou cobertura. Nesses casos, ocorrem muitas vezes situações indesejáveis como a criação de animais, existência de catadores e habitações, além da utilização de rejeitos como alimentos, o que também foram proibidas. Rauber (2011) cita que a PNRS criminaliza as 
condutas de abandono ou tratamento inadequado de produtos ou substâncias tóxicas perigosas, ou que façam mal à saúde humana ou ao meio ambiente, sendo que seja qual for sua origem ou periculosidade não podem ser dispostos em corpos hídricos, queimados a céu aberto ou em recipientes sem autorização por órgão competente.

No tocante, a Lei ainda ressalta que a disposição final ambientalmente adequada dos rejeitos, deveria ser implantada em até quatro anos após a data de publicação da PNRS, ou seja, até 2014. No entanto, a meta não foi atingida em sua totalidade, verificando-se a necessidade de compreender a situação atual dos municípios brasileiros, em relação a tal aspecto, e por quais motivos não foi possível o alcance da mesma.

\title{
2.1.1 Planos de Resíduos Sólidos (PRS)
}

Emílio et al. (2014) define a palavra plano, como sendo um documento onde se fixam todos os elementos necessários a objetivação ao que se pretende, ou seja, os PRS devem conter todos os instrumentos, objetivos e metas da PNRS para que os impactos negativos gerados pelos resíduos sejam minimizados e extinguidos do meio ambiente.

De acordo com Guerra (2012),

\begin{abstract}
O plano de resíduos é um documento formal e vinculativo que reproduz o modelo de gestão e gerenciamento de resíduos adotado por determinado ente federativo ou setor empresarial, por meio do qual são enumeradas todas as ações indispensáveis para o alcance das pretensões e proposições nele inferidas (GUERRA, 2012).
\end{abstract}

Os PRS devem ser elaborados abrangendo quatro níveis: Nacional, Estadual, Municipal e empresarial, sendo que cada um possui seus próprios conteúdos mínimos, e cada ente deverá elaborar o seu plano de acordo com sua competência.

O Plano Nacional dos Resíduos Sólidos foi elaborado através do Comitê Interministerial, que é composto por 12 ministérios e coordenado pelo Ministério do Meio Ambiente que tem responsabilidade de elaborar e implementar o mesmo. Este, deve manter a relação com os demais Planos Nacionais (Mudanças do Clima, de Recursos Hídricos, de Saneamento Básico, de Produção e Consumo Sustentável e demais) abordando e contemplando a 
problemática dos mais diversos tipos de resíduos gerados, alternativas de gestão e gerenciamento, planos de metas, programas, projetos e ações que terão vigência de vinte anos para sua implantação e devem ser atualizados de forma geral, a cada quatro anos.

O Plano Nacional de Resíduos Sólidos publicado em agosto de 2012 em sua versão final ficou composto por 29 diretrizes, 170 estratégias e 28 metas que orientam o Brasil para implantar uma gestão ambientalmente correta aos resíduos sólidos, diminuindo os impactos negativos, aumentando a qualidade de vida e melhorando o cenário até 2031, o que deve ser atualizado a cada quatro anos.

Sabe-se que a União, assim como, os estados e municípios tiveram dois anos para elaborar seus planos de gestão de resíduos sólidos. A União conseguiu cumprir com seus prazos, estando os estados, a partir de agosto de 2012 condicionados ao Plano Estadual de Resíduos Sólidos (PERS) apresentando seu conteúdo mínimo disposto no art. 17 da Lei 12.305/2010. Este, deve ter duração de vinte anos e revisões a cada quatro anos, contemplando todo seu território, priorizando o incentivo à cooperação para viabilizar a gestão regionalizada dos resíduos, sempre de acordo com os demais objetivos, diretrizes e legislações pertinentes.

Dos estados da região Sul do Brasil, que compreendem Rio Grande do Sul (RS), Santa Catarina (SC) e Paraná (PR), apenas SC apresentou o Plano Estadual de Gestão Integrada de Resíduos Sólidos (PEGIRS) em novembro de 2012. O PR lançou seu PEGIRS em junho de 2013 e já o RS iniciou a sua elaboração em 2012 se estendendo até 2015, o que de certa forma acaba refletindo nos municípios, além de outros fatores, principalmente econômicos e culturais.

Em 2015, o Ministério do Meio Ambiente relatou que dos 497 municípios do estado do RS, 231 deles, ou seja, cerca de 46,48\% não possuíam PMGIRS. Esses 231 municípios são compostos principalmente por municípios de pequeno a médio porte os quais não possuem acesso aos recursos financeiros da União, sendo que, 62 municípios, correspondente a 26,8\%, faziam uso de técnicas de disposição inadequada de seus resíduos (MMA, 2015). De acordo com Bezerra \& Bezerra (2015), é de notório conhecimento, que existem limitações orçamentárias e principalmente técnicas, que impedem os pequenos 
municípios de elaborar seus PGIRS e que, por esse motivo, acabam não sendo contemplados com os recursos, os quais sem recurso, não há cumprimento da Lei.

Em Santa Catarina no ano de 2015, dos 295 municípios que compõe o Estado, 105 municípios, que correspondem a 35,6\% ainda não possuíam o PGIRS (MMA, 2015). De acordo com a Agência Intermunicipal de Regulação do Médio Vale do Itajaí em 2014 o estado de Santa Catarina investiu 5 milhões de reais para cooperação na elaboração dos planos e projetos de resíduos sólidos em 12 das 16 regiões em que foram divididos os 295 municípios. A agência menciona ainda que no ano de 2014, 14\% dos municípios já tinham o PMGIRS, 20\% estavam aguardando licitação para contratar a empresa responsável pela elaboração do plano, e 66\% estavam em fase de elaboração. A perspectiva era de que até o final de 2014 todos os 295 municípios já teriam seu PMGIRS prontos. Porém, constatou-se que em 2015, cerca de 105 municípios ainda não possuíam o PMGIRS, porém todos os municípios destinavam seus resíduos em aterros sanitários geralmente localizado fora do município (MMA, 2015).

O estado do Paraná, compreendido por 399 municípios possui a maior abrangência, tendo em 2015 apenas 75 municípios, correspondente a 18,8\% sem o PMGIRS, porém 46,6\% destes ainda faziam uso de técnicas consideradas ilegais e inadequadas pela Política Nacional de Resíduos Sólidos (MMA, 2015).

De forma geral, no Brasil em 2015, dos 5.570 municípios brasileiros, 3.245 municípios, correspondentes a 58,3\% não possuem PMGIRS (MMA, 2015). Dentre os municípios que afirmaram possuir o PMGIRS no Brasil, 31 deles possuem inserido no Plano de Saneamento Básico (PSB) contendo um item específico para a Gestão de Resíduos Sólidos, que de acordo com o Decreto 7.404/2010 ( $§ 2^{\circ}$ do art. 54), o componente de limpeza urbana e manejo de resíduos sólidos urbanos pode estar inserido nos PSB e podem ser simplificados para municípios com menos de 20 mil habitantes, mas estes são válidos desde que respeitem o conteúdo mínimo proposto para ambos os documentos legais, que são regulamentados pelo art.19 da Lei 12.305/2010, art. 51 do Decreto 7.404/2010 para caso simplificado e Lei ํㅜ 11.445/2007. 
Para a Lei 12.305/2010, os PMGIRS não possuem um prazo para elaboração e entrega dos mesmos, apenas a partir de agosto de 2012 se não tiverem o PMGIRS ficam sem acesso a recursos da União e outros por ela controlados que poderiam ser utilizados em serviços relacionados à gestão dos resíduos sólidos. Além disso, a não elaboração do plano acarreta em outras implicações, como o não conhecimento do panorama dos resíduos gerados em seu território tanto quantitativa e qualitativamente, não tendo ações e projetos que abranjam a reciclagem, redução, coleta, disposição ambientalmente adequada, enfim todo o conjunto social, econômico e ambiental.

\subsubsection{Disposição final ambientalmente adequada}

Com a Lei 12.305/2010 ocorreu uma preocupação sobre a gestão de resíduos e sua disposição ambientalmente adequada, trazendo como meta a eliminação de lixões e locais considerados inadequados até 2014, porém, a meta não foi alcançada e novos prazos foram elaborados. Os resíduos sólidos devem ser aproveitados e os rejeitos, ou seja, aquilo que não pode ser reaproveitado e reciclado, destinado para aterros sanitários.

Na figura 1 é possível verificar a situação do Brasil quanto à gestão de resíduos sólidos nos anos de 2010, 2014 e 2015 de acordo com relatórios da Associação Brasileira de Resíduos Especiais de Limpeza Pública. Verifica-se que no decorrer dos anos tem-se um aumento na produção de resíduos sólidos que se deve ao aumento populacional, sendo que não foi acompanhado de técnicas adequadas de destinação. No ano de 2010 cerca de $11 \%$ dos resíduos sólidos produzidos deixaram de ser coletados, apresentando uma melhora de 2\% para os anos de 2014 e 2015. Quanto à destinação ambientalmente inadequada está longe para ter-se um fim. De 2010 para 2015 praticamente não houve melhoras quando verificado os volumes de resíduos dispostos inadequadamente, tendo-se uma diminuição de menos de $1 \%$. 
Figura 1: Situação do Brasil quanto a gestão de resíduos sólidos.

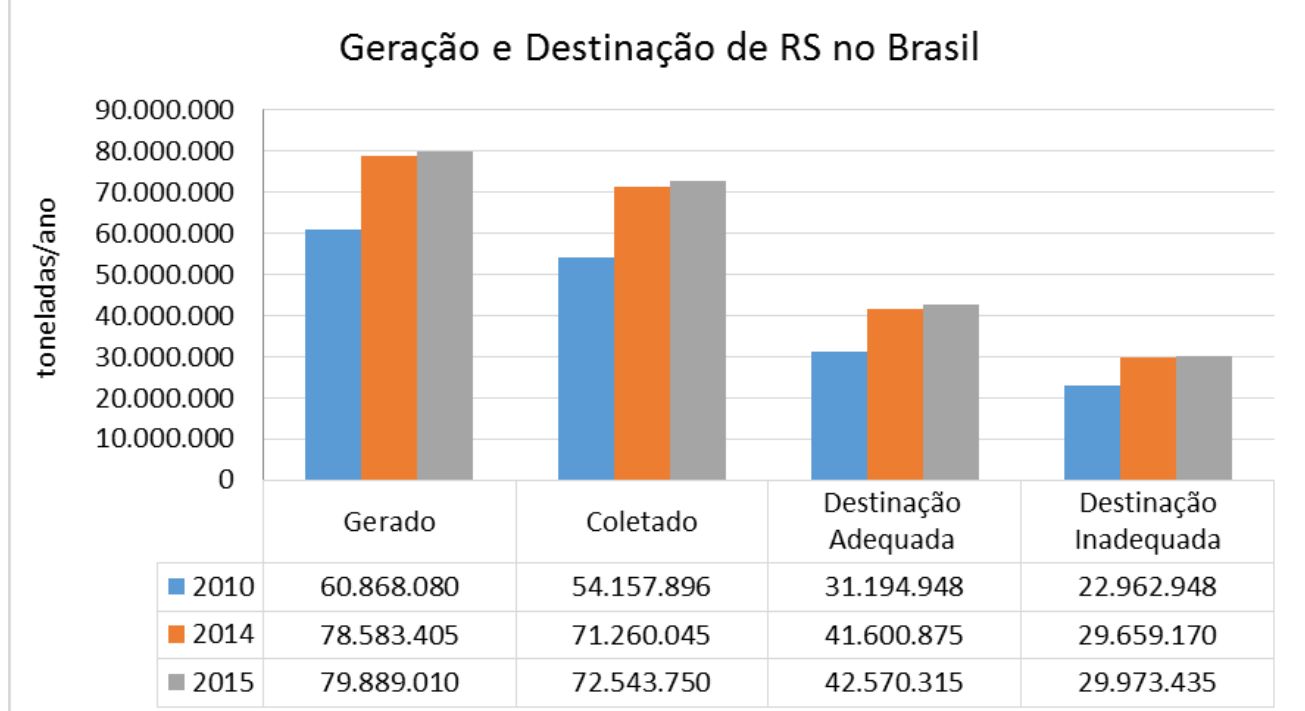

Fonte: ABRELPE (2010); ABRELPE (2014) e ABRELPE (2015).

$\mathrm{Na}$ região Sul do Brasil, no ano de 2010 teve-se 1.188 municípios participantes da pesquisa realizada pela ABRELPE, com uma coleta abrangendo $91,4 \%$ dos resíduos produzidos sendo destinados adequadamente $60,4 \%$ dos resíduos coletados (Figura 2). De acordo com as técnicas de disposição de resíduos, em 2010, dos três estados da região Sul, 58,25\% correspondente a 692 municípios faziam uso de aterros sanitários, 31,06\% (369 municípios) faziam uso de aterros controlados e 10,7\% (127 municípios) faziam uso de lixões (ABRELPE, 2010).

Quando comparados com o ano de 2015, a Região Sul teve 1.191 municípios participantes, abrangendo uma coleta de $94,37 \%$ dos resíduos produzidos onde $70,86 \%$ foram destinados adequadamente em aterros sanitários (Figura 2). Verifica-se uma melhora na gestão de resíduos sólidos na Região Sul quando comparado em nível de Brasil, tendo-se avanços na universalização da coleta seletiva e destinação adequada. 
Figura 2: Situação da Região Sul quanto a gestão de resíduos sólidos.

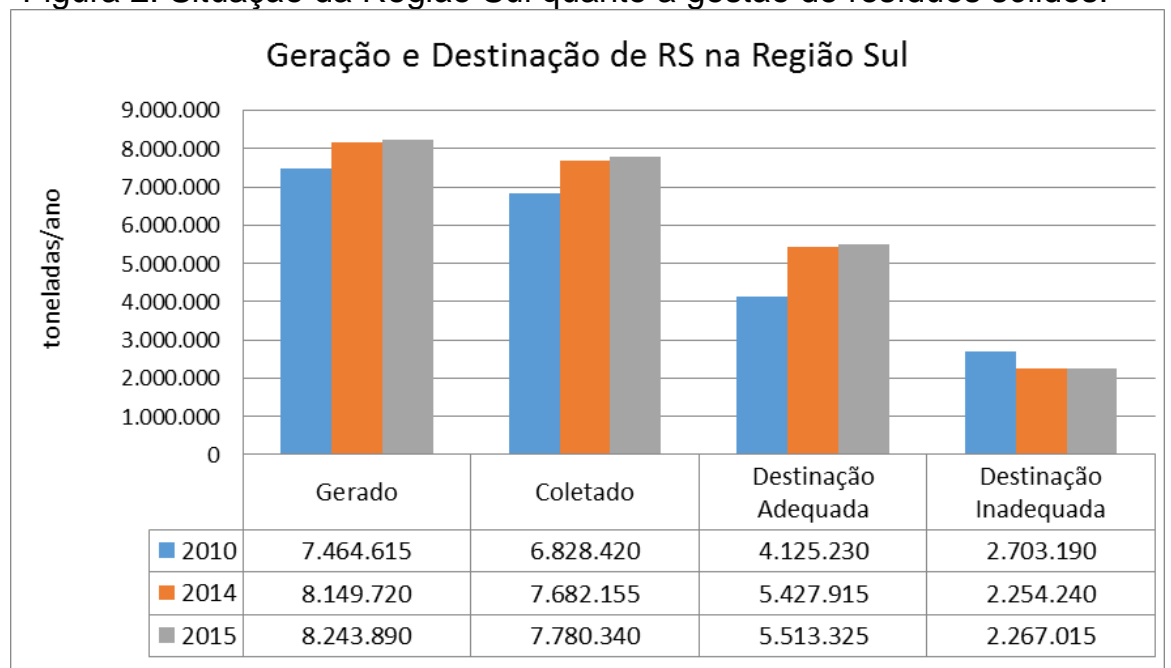

Fonte: ABRELPE (2010); ABRELPE (2014) e ABRELPE (2015).

Mais especificamente dos estados da região Sul, o Paraná em 2010, antes mesmo da obrigatoriedade quanto a eliminação dos lixões e aterros controlados destinava $69,1 \%$ dos resíduos produzidos em aterros sanitários (Figura 3). Porém, cinco anos depois, não há uma melhora tão significativa, tendo-se um aumento de apenas 1,3\% quanto à disposição adequada dos resíduos sólidos coletados dentro do estado (Figura 3).

Figura 3: Situação do estado do Paraná quanto a gestão de resíduos sólidos.

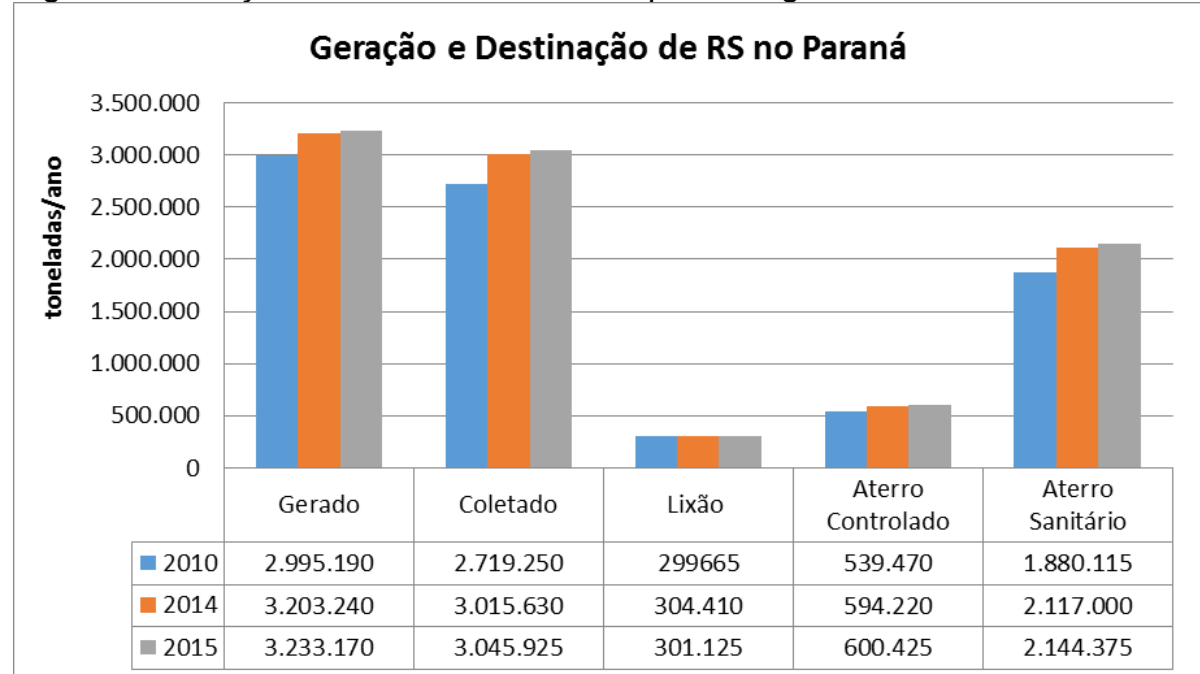

Fonte: ABRELPE (2010); ABRELPE (2014) e ABRELPE (2015).

Já Santa Catarina em 2010, tinha como disposição dos resíduos gerados e coletados em seu território com $71,3 \%$ em aterros sanitários, $17,1 \%$ em aterros controlados e $11,6 \%$ em lixões (Figura 4) (ABRELPE, 2010). Em 
2015, teve-se uma melhora de $0,8 \%$ quanto à disposição adequada dos resíduos sólidos urbanos (Figura 4).

Figura 4: Situação do estado de Santa Catarina quanto a gestão de resíduos sólidos.

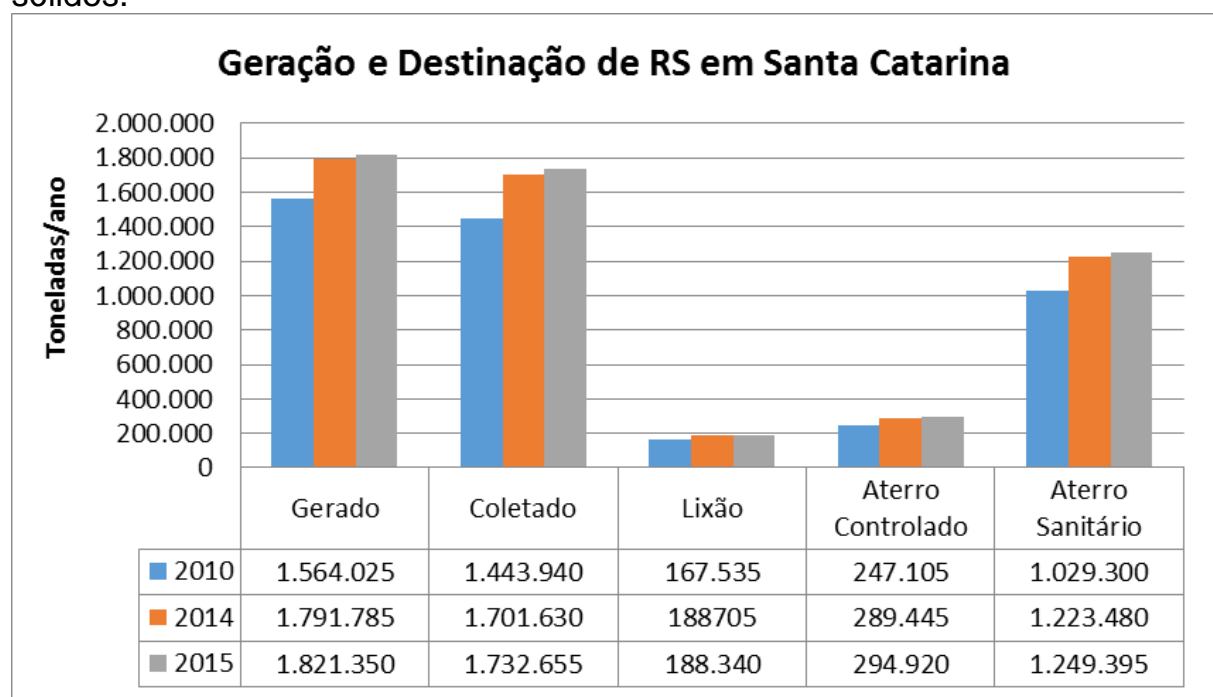

Fonte: ABRELPE (2010); ABRELPE (2014) e ABRELPE (2015).

O Rio Grande do Sul em 2010 tinha como destinação para os resíduos sólidos urbanos produzidos e coletados em seu território, 69,5\% em aterros sanitários, $17,6 \%$ em aterros controlados e 12,9\% em lixão (Figura 5) (ABRELPE, 2010). Em 2015, apresentou uma melhora de 1,1\% na destinação adequada de seus resíduos (Figura 5).

Figura 5: Situação do estado do Rio Grande do Sul quanto a gestão de resíduos sólidos.

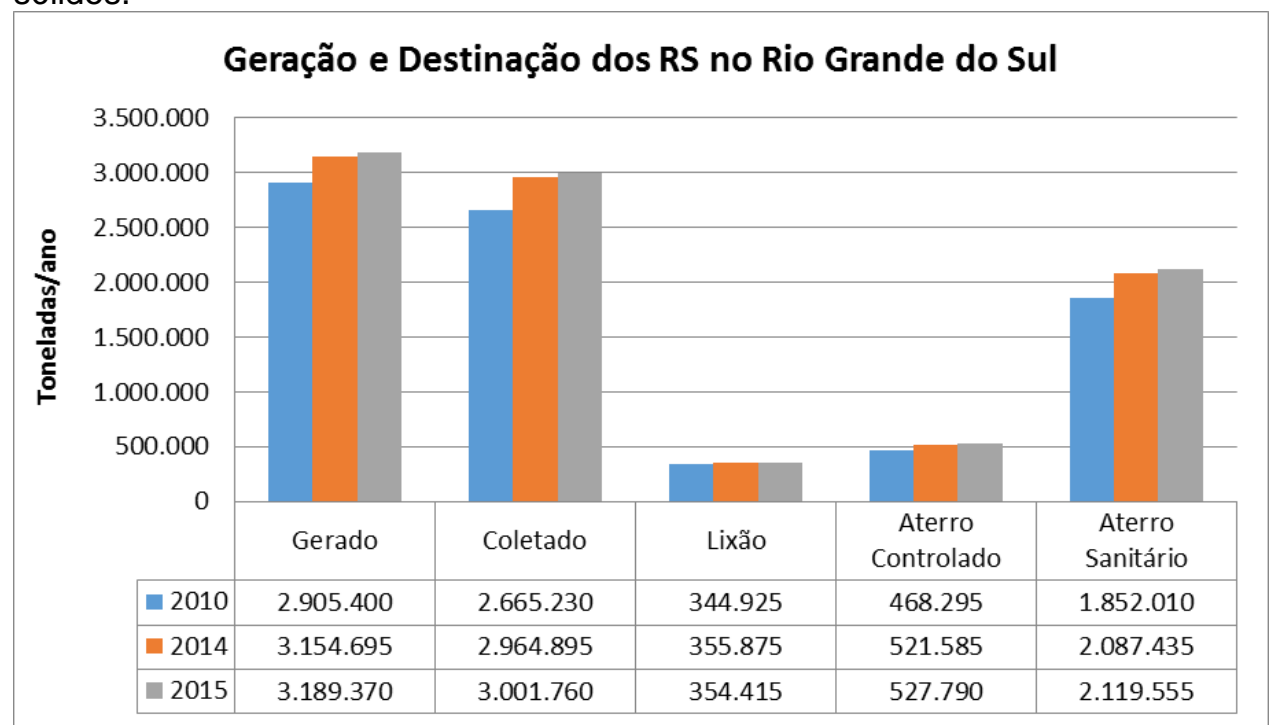

Fonte: ABRELPE (2010); ABRELPE (2014) e ABRELPE (2015). 
Em todos os estados da região Sul teve-se uma melhora comparando-se a destinação adequada do ano de 2010 para 2015, porém, verifica-se que muitos municípios ainda fazem uso de locais inadequados para dispor seus resíduos. Para o Ministério do Meio Ambiente, no Rio Grande do Sul em 2015, 128 municípios (62 municípios sem PMGIRS e 66 com o PMGIRS), correspondente a 25,75\% faziam uso de disposição inadequada de seus resíduos na forma de aterros controlados. No Paraná, 31 municípios $(7,77 \%)$ faziam uso de lixão e 132 municípios (33,08\%) utilizavam de aterros controlados, correspondente a um total de 40,85\% dos municípios com destinação incorreta de seus resíduos produzidos, mesmo após 0 encerramento do prazo para adequação (MMA, 2015). Em Santa Catarina, no ano de 2015, todos os municípios destinam seus resíduos para aterros sanitários, sendo considerado um exemplo de estado para todo o país, pois é o único que conseguiu dar fim aos lixões e aterros controlados (MMA, 2015). Porém, de acordo com dados da ABRELPE (2015) Santa Catarina ainda destina $27,9 \%$ dos seus resíduos em lixões e aterros controlados, tendo-se inconsistência de dados, dificultando afirmações quanto a inexistência de disposição inadequada.

De forma geral, ressalta-se que o prazo de quatro anos não foi suficiente para que os municípios conseguissem se adequar, onde principalmente os pequenos municípios tem maior dificuldade, por isso a necessidade de elaboração dos PEGIRS, para que junto com outros municípios sejam formados consórcios para solução e destinação correta dos resíduos.

De acordo com Maia et al. (2014), a Política Nacional dos Resíduos Sólidos propõe medidas de incentivos para realização de consórcios públicos regionais com o objetivo de ampliar a capacidade de gestão das administrações municipais, por meio de ganhos de escalas e redução de custos no caso de compartilhamento de sistemas de coleta, tratamento e destinação dos resíduos sólidos, sendo que os estados e municípios podem juntos procurar a melhor forma de gerir os seus resíduos. Assad \& Siqueira (2016) afirmam que os décimos de melhora à destinação dos resíduos sólidos, não só na região Sul, mas em todo Brasil, demostram que a gestão dos resíduos sólidos não tem sido prioridade em boa parte dos municípios brasileiros. 
De acordo com Gabriela Otero, coordenadora técnica da ABRELPE, destaca-se que desde 1981, quando o Brasil aprovou a Política Nacional do Meio Ambiente (Lei no 6.938, de 31/08/1981), já definiu os lixões como locais impróprios para disposição dos resíduos proibindo-os, assim como as demais políticas, onde a Lei dos Crimes Ambientais (Lei no 9.605, de 12/02/1998), que considerou os lixões como crime ambiental, passível de pena e cinco anos de reclusão, já trazendo a necessidade de criar técnicas adequadas de disposição (ASSAD \& SIQUEIRA, 2016). Então surge a Política Nacional dos Resíduos Sólidos em 2010, trazendo como meta o fechamento dos lixões e aterros controlados até agosto de 2014, e simplesmente nada acontece, mesmo sabendo que a mais de 30 anos atrás já se definia e orientava que os lixões e aterros controlados são locais impróprios para disposição de resíduos, os quais já deveriam ter sido fechados.

Assad e Siqueira (2016) citam que muitos profissionais e educadores, consideram que a PNRS reflete uma gestão de resíduos sólidos urbanos de forma moderna, ampla, com segurança, sem desperdício, rápida e eficiente. Contudo os autores ressaltam que há dificuldades para concretizar uma gestão adequada, relacionadas à falta de recursos, pessoal técnico capacitado, qualificado e principalmente vontade política.

Os municípios de pequeno porte não têm condições financeiras, políticas e estruturais para construção de um aterro sanitário, primeiro devido a questão de espaço para construção, necessidade de maquinário para execução das atividades, veículos e suporte para coleta seletiva, logística reversa, além de pessoas capacitadas na operação do aterro para que se tenha o funcionamento correto e menor impacto possível. Mas isso, se verificada a PNRS, leva em consideração essa dificuldade, por isso, prioriza os consórcios públicos entre dois ou mais municípios, para que esses custos sejam divididos e o impacto seja localizado.

Já Gabriela Otero, coordenadora técnica da ABRELPE, considera que não faltam recursos nem profissionais capacitados, e sim, oportunidades para profissionais atuarem na gestão de resíduos sólidos dentro dos municípios, sendo necessária também a articulação política, pois deve ocorrer a integração das secretarias de meio ambiente, saúde, saneamento, educação e priorização da gestão dos resíduos (ASSAD E SIQUEIRA, 2016). 
Assim, os lixões e locais inadequados vão existindo, as sanções penais, administrativas, as proibições e todas essas diretrizes, nunca aconteceram na prática quanto aos resíduos, mas existem e está previsto em legislações (CALIXTO, 2015). Diante dessa flexibilidade perante a lei, os municípios têm abertura, sendo que passaram a pressionar por certas mudanças na legislação, com o primeiro pedido, relacionado à prorrogação para o fim dos lixões, onde o texto contém prazos dobrados até 2018 para fechamento dos lixões, sem perceber que isso afeta toda a sociedade perante seus impactos.

\subsubsection{Resíduos Gerados e Reciclagem}

A Política Nacional dos Resíduos Sólidos orienta para que todas as empresas e geradores de resíduos deem uma destinação adequada para seus resíduos produzidos e seja ela qual for à situação, sempre deve ser levado em conta e ser prioridade 0 art. 9 da Lei, que dispõe sobre a gestão e gerenciamento de resíduos sólidos, seguindo a preferência de não geração, redução, reutilização, reciclagem, tratamento de resíduos sólidos e disposição final ambientalmente adequada.

Ramos (2014) cita que o propósito fundamental da PNRS, em face da crescente produção de resíduos sólidos, é estimular a coleta seletiva, a reciclagem e o reaproveitamento de tudo o que for possível, sendo a última etapa a destinação correta em aterros sanitários, ou seja, apenas daquilo que não pode mais ser reaproveitado, o que chamamos de rejeitos.

De acordo com a ABRELPE, comparando-se os resíduos produzidos no ano de 2010 para 2015, verifica-se que o Brasil apresentou um aumento da geração per capita de 3,31\%, porém, a geração total atingiu um crescimento de $31,2 \%$. As regiões do Centro-Oeste e Sudeste em 2015 apresentaram a maior geração per capita do país, estando a região Sul com os menores índices. Quando verificados a geração total de resíduos, ocorre uma mudança no cenário estando a região Sudeste e Nordeste como as maiores produtoras. Para Gonçalves et al. (2016) a região Sudeste do Brasil, concentra o maior volume de produção e coleta de resíduos sólidos, fato que é resultante do processo histórico de formação econômica do território nacional, que concentrou nestas áreas alto índice populacional. 
A região Sul do Brasil quando comparados a geração de resíduos do ano de 2010 a 2015, apresentou uma diminuição na geração per capita de $12 \%$, passando de $0,879 \mathrm{~kg} / \mathrm{hab} /$ dia para $0,773 \mathrm{~kg} / \mathrm{hab} /$ dia. Na geração total de resíduos entre 2010 a 2015 há um aumento de 10,4\% para a região Sul, sendo o estado do Paraná o maior gerador per capita e total, seguido do estado do Rio Grande do Sul e Santa Catarina.

Para que os resíduos possam ser reciclados, reutilizados e destinados adequadamente é necessário que os mesmos sejam coletados. De acordo com o Instituto Brasileiro de Geografia e Estatística- IBGE (2010) a alta geração de resíduos deve ser relacionada com a realização da coleta seletiva e não com sua destinação, sendo que nas regiões onde se encontram a maior parte da população e a maior geração média por indivíduo/dia, apresentam índices de disposição regular em aterros sanitários maiores que as de menor densidade populacional.

No Brasil, em comparação entre os anos de 2010 a 2015 teve-se um aumento no índice de coleta de 1,8\%, sendo que a região Sudeste apresenta 0 melhor índice, seguidos da região Centro-Oeste e Sul. Na região Sul entre os anos de 2010 e 2015 houve um crescimento de 2,83\% no índice de coleta com 1.067 municípios com iniciativas de coleta seletiva e 124 municípios sem qualquer iniciativa. Percebe-se que o crescimento dos índices de coleta é mais significativo que o crescimento da destinação adequada, mas que de certa forma pode ser o começo, visto que sem a coleta, não se tem a correta destinação do resíduo e nem o possível aproveitamento energético do mesmo.

A logística reversa está associada ao aproveitamento dos resíduos sólidos, e a PNRS traz esse instrumento de gestão, dando certo apoio ao ciclo de vida do produto e a necessidade de reaproveitamento de suas energias. Assim, Leite (2002), define a logística reversa como um processo de planejamento, implementação e controle da eficiência, do custo efetivo do fluxo de matérias-primas, estoques de processo, produtos acabados e as respectivas informações, desde o ponto de consumo até o ponto de origem, com o propósito de recapturar valor ou adequar o seu destino.

De acordo com os relatórios apresentados, os setores de embalagens de agrotóxicos, óleos lubrificantes e pneus inservíveis contam com ações estruturadas para retorno dos materiais descartados, e têm se destacado no 
incentivo à logística reversa, onde em 2011, de acordo com ABRELPE (2014), cerca de 34.202 toneladas de embalagens de agrotóxicos, 40 milhões de unidades de embalagens e óleos lubrificantes e 320 mil toneladas de pneus foram coletados e destinados. Quando comparadas ao ano de 2014 com dados extraídos da mesma fonte, 42.646 toneladas de embalagens de agrotóxicos, 80 milhões de unidades de embalagens e óleos lubrificantes e 445 mil toneladas de pneus que foram coletados e destinados, aumentando seu volume de 2011 para 2014.

Mas a logística reversa ainda é um desafio para o Brasil, quando comparados a PNRS, pois os pneus, óleos lubrificantes e agrotóxicos já possuíam legislação própria a mais de 10 anos, sendo incluídos pela PNRS as lâmpadas fluorescentes, de vapor de sódio e mercúrio e de luz mista e ainda produtos eletroeletrônicos e seus componentes, os quais foram previstos o retorno de suas embalagens pela lei 12.305/2010, mas ainda não constam em valores para serem avaliados (LEITE, 2014).

Quando se trata da reciclagem os materiais de alumínio, papel e plástico são os principais e mais participativos do panorama de reciclagem do Brasil. De acordo com Paiva (2015), em matéria publicada pelo Jornal Hoje, os brasileiros jogam fora 76 milhões de toneladas de lixo, onde destes 30\% poderiam ser reaproveitados, mas só 3\% vão para a reciclagem. De acordo ainda com o autor, em dez anos, o número de municípios que implantaram programas de reciclagem aumentou de 81 para mais de 900, mas isso não representa nem $20 \%$ das cidades. Sendo que algumas delas, como por exemplo, Curitiba, apresenta o melhor programa de reciclagem, com produção de 1,5 mil toneladas diária, onde $70 \%$ dos resíduos são reciclados e reaproveitados, assim, de certa forma, os dados quanto Brasil acabam mascarados, por algumas cidades que praticam o ato de reciclagem em altos índices e outros que não realizam a atividade.

De acordo com o panorama de resíduos sólidos, apresentado pelo ABRELPE no ano de 2014, têm-se os dados de reciclagem somente do papel, alumínio e plástico, representando os anos de 2009 a 2011, onde não há uma diferença significativa na porcentagem de reciclagem dos devidos produtos. Em 2011 , 35,3\% do alumínio geral foi reciclado, sendo destas 97,9\% latinhas; o papel teve $45,7 \%$ da sua produção reciclada e já o plástico foi reciclado $20,9 \%$ sendo $58,9 \%$ garrafas pet. 
Gama (2016), em uma pesquisa realizada pela Abralatas em 2014, cita que o Brasil é o maior reciclador mundial de latas de alumínio, com 98,4\% das latas recicladas. De acordo com a mesma pesquisa, foram comercializadas no mercado brasileiro 294,2 mil toneladas de latas onde 289,5 mil toneladas foram recicladas, de forma que retornou a economia cerca de $R \$ 845$ milhões.

De acordo com o Portal Brasil (2014), o setor de reciclagem movimenta cerca de $R \$ 12$ bilhões por ano no Brasil, sendo que o serviço está presente em apenas $8 \%$ dos municípios brasileiros. $O$ autor ainda cita que se perde, em torno de $R \$ 8$ bilhões anualmente por deixar de reciclar os resíduos que são encaminhados aos aterros ou lixões.

O Brasil está caminhando para aumentar a porcentagem de reciclagem, mas falta integração entre os cidadãos, empresas e poder público, além de programas que atendam todos os tipos de resíduos e que os mesmos sejam coletados e reciclados quando possível.

\section{CONSIDERAÇÕES GERAIS}

A problemática dos resíduos sólidos vem acompanhando a sociedade há muitos anos, sendo a Política Nacional dos Resíduos Sólidos, instituída pela Lei 12.305 de 2010 um grande marco, porém, não estabeleceu uma grande mudança no comportamento da sociedade quanto aos resíduos.

A elaboração dos Planos de Resíduos Sólidos em esfera de município, mesmo não tendo um prazo, muitos deles ainda não foram realizados, o que acarreta consequentemente na não solução das problemáticas quanto aos resíduos, de forma que as alternativas de gestão, programas, projetos, não abrangem de forma eficiente os resíduos gerados, tendo-se a ineficiência.

A disposição inadequada dos resíduos sólidos ainda existe desrespeitando a Lei. No Brasil entre os anos de 2010 a 2015, teve-se uma diminuição de aproximadamente $1 \%$ relacionada a destinação inadequada. $\mathrm{A}$ geração dos resíduos aumenta a cada ano, junto com ele aumentam em ritmo muito mais lento a coleta seletiva, reciclagem, reaproveitamento, logística reversa e destinação adequada. Na região Sul os números são um pouco mais animadores, mas ainda, se tem muitos municípios sem Planos de Resíduos 
Sólidos não realizando a gestão necessária para atender os requisitos impostos pela legislação.

Há certa dificuldade em realmente afirmar-se essa melhora quanto a gestão e gerenciamento dos resíduos, pois há falta de informação, transparência e inconsistência dos dados, o que acaba trazendo determinadas distorções entre as fontes; e isso afeta quanto aos avanços da PNRS, onde as medidas adotadas em determinados setores pelo fato de não se conhecer quantitativamente pode vir a prejudicar os demais segmentos. Além de que, sabe-se hoje, que muitos dos resíduos produzidos, dispostos inadequadamente e reciclados não estão sendo quantificados, pois ainda se tem muitos serviços informais, não se conseguindo demonstrar a realidade.

Verifica-se que a situação está bastante distante do que foi discutido e registrado na Lei 12.305 de 2010 durante seus 20 anos de debate e construção, e assim como foi demorada a criação da PNRS, está sendo ainda mais lenta a evolução da gestão dos resíduos sólidos, tendo-se uma barreira para aplicação da PNRS.

Quanto a solução para aplicação da PNRS e alcance dos seus objetivos e metas, nada mais é do que um dos instrumentos da PNRS, educação ambiental, que entra como peça chave para o sucesso, assim como investimentos por parte do poder público em coleta seletiva, reciclagem, logística reversa e demais instrumentos para uma melhor gestão quanto aos resíduos.

\section{REFERÊNCIAS}

ABRELPE - Associação Brasileira de Empresas de Limpeza Pública e Resíduos Especiais. Panorama de Resíduos Sólidos no Brasil- 2010. São Paulo: Abrelpe, 2010.

ABRELPE - Associação Brasileira de Empresas de Limpeza Pública e Resíduos Especiais. Panorama de Resíduos Sólidos no Brasil- 2014. São Paulo: Abrelpe, 2014.

ABRELPE - Associação Brasileira de Empresas de Limpeza Pública e Resíduos Especiais. Panorama de Resíduos Sólidos no Brasil- 2015. São Paulo: Abrelpe, 2015. 
ABREU, Luiza Bezamat de; PALHARES, Maria Claudia. O destino do lixo.Rio de Janeiro-RJ: PUC, 2006.

Agência Intermunicipal de Regulação do Médio Vale do Itajaí (AGIR). Municípios Catarinenses Cumprem Meta da Política Nacional de Resíduos Sólidos e Eliminam Lixões. Disponível em: http://www.agir.sc.gov.br/11-educacao-ambiental/355-municipios-catarinensescumprem-meta-da-politica-nacional-de-residuos-solidos-e-eliminam-lixoes.

Acesso em: 29 de out. 2016.

ASSAD, Leonor; SIQUEIRA, Thais. Lixões continuam por toda parte. Ciência e Cultura, v. 68, n. 2, p. 08-10, 2016.

BEZERRA, Francisco Carlos Barros; BEZERRA, Ana Keuly Luz. Política Nacional de Resíduos Sólidos e as dificuldades de municípios pequenos. Revista Jus Navigandi, Teresina, ano 20, n. 4508, 4 nov. 2015. Disponível em: <https://jus.com.br/artigos/43851>. Acesso em: 25 out. 2016.

BRASIL, M. M. A. Ministério do Meio Ambiente. Plano Nacional dos Resíduos Sólidos. Brasília: $\quad M M M / S B F F, \quad 2016 . \quad$ Disponível: http://www.mma.gov.br/pol\%C3\%ADtica-de-res\%C3\%ADduos-s\%C3\%B3lidos. Acesso em: 25 out. 2016.

BRASIL, M. M. A. Ministério do Meio Ambiente. "Parceria com Governo Federal, Comissão Interinstitucional de Educação Ambiental (CIEA) e Plano de Gestão Integrada de Resíduos Sólidos". 2015. Brasília: MMA/SBFF, 2015. Disponível em: http://sinir.gov.br/web/guest/2.5-planosmunicipais-de-gestao-integrada-de-residuos-solidos. Acesso em: 29 de out. 2016.

BRASIL, PORTAL. Reciclagem atinge apenas $8 \%$ dos municípios brasileiros. Disponível em: $h$ ttp://www. brasil. gov. br/meioambiente/2012/04/reciclagem-atingeapenas-8-porcento-dos-municipios-

brasileiros>.

BRASIL, SINIR. Sistema Nacional de Informação dos Resíduos. Plano Nacional dos Resíduos Sólidos.Disponível em: http://www.sinir.gov.br/web/guest/plano-nacional-de-residuos-solidos. Acesso em: 29 de out. 2016.

BRASIL. Lei no 12.305, de 2 de agosto de 2010. Institui a Política Nacional de Resíduos Sólidos; altera a Lei no 9.605, de 12 de fevereiro de 1998; e dá outras providências. Diário Oficial da República Federativa do Brasil, Brasília, DF, 2010. 
CALIXTO, B. Lixão que não acaba mais. Revista Época. 2015. Disponível em: http://epoca.globo.com/colunas-e-blogs/blog-do-planeta/noticia/2015/07/lixaoque-nao-acaba-mais.htmlAcesso em: 29 de out. 2016.

COSTA, Edimilson Rodrigues da. Uma visão comentada sobre a lei da PNRS. 2015.

Disponível em: http://www.revistapetrus.com.br/uma-visaocomentada-sobre-alei-da-pnrs . Acesso em: 28 out. 2016.

DEMAJOROVIC, Jacques; BESEN, Gina Rizpah; RATHSAM, Alexandre Arico. Os desafios da gestão compartilhada de resíduos sólidos face à lógica do mercado. Diálogos em ambiente e sociedade no Brasil, v. 1, 2006.

EMÍLIO, Patrícia Raysel et al. POLÍTICA NACIONAL DE RESíDUOS SÓLIDOS: o poder transformador e integrador da gestão jurídica dos resíduos sólidos. 2014.

FELICORI, Thaís de Carvalho et al. Identificação de áreas adequadas para a construção de aterros sanitários e usinas de triagem e compostagem na mesorregião da Zona da Mata-Minas Gerais. 2015.

GAMA, M. Brasil é campeão mundial na reciclagem de latas de alumínio. 2016. Folha de São Paulo. In:http://www1.folha.uol.com.br/seminariosfolha/2016/06/1784363-brasil-ecampeao-mundial-na-reciclagem-de-latas-de-aluminio.shtml. Acesso em: 29 de out. 2016.

GÓES, Helivia Costa. Coleta seletiva, planejamento municipal e a gestão de resíduos sólidos urbanos em Macapá/AP. Planeta Amazônia: Revista Internacional de Direito Ambiental e Políticas Públicas, n. 3, p. 45-60, 2012.

GONÇALVES, Marcelino de Andrade et al. Um estudo comparado entre a realidade brasileira e portuguesa sobre a gestão dos resíduos sólidos urbanos. Sociedade \& Natureza, v. 28, n. 1, p. 9-20, 2016.

GUERRA, Sidney. Resíduos sólidos: comentários à Lei 12.305/2010. Rio de Janeiro: Forense, 2012. p. 137.

INSTITUTO BRASILEIRO DE GEOGRAFIA E ESTATÍSTICA - IBGE. Pesquisa Nacional de Saneamento Básico. Rio de Janeiro: IBGE, 2010.

LEITE, Paulo Roberto. Logística reversa: nova área da logística empresarial. Revista Tecnologística, maio/2002. São Paulo, Edit. Publicare, 2002. 
LEITE, Paulo Roberto. Desafios da Logística Reversa de pós consumo no Brasil. Revista Tecnologística, maio, p. 64-69, 2014.

MAIA, Hérika Juliana Linhares et al. Política Nacional de resíduos sólidos: um marco na legislação ambiental brasileira. POLÊMICA, v. 13, n. 1, p. 1070-1080, 2014.

NAGASHIMA, Lucila Akiko et al. Gestão integrada de resíduos sólidos urbanos-uma proposta para o município de Paranavaí, Estado do Paraná, Brasil-doi: 10.4025/actascitechnol. v33i1. 581. Acta Scientiarum. Technology, v. 33, n. 1, p. 39-47, 2011.

OLIVEIRA, B. O. S. Avaliação dos impactos ambientais do solo e da água na área de disposição final de resíduos sólidos urbanos em HumaitáAM.2013. Manaus: UFAM, 2013. 90 p.

PAIVA, R. Apenas 3\% de todo lixo produzido na Brasil é reciclado. 2015. Jornal Hoje. In: http://g1.globo.com/jornal-hoje/noticia/2015/04/apenas-3-detodo-o-lixo-produzido-no-brasil-e-reciclado.html. Acesso em: 29 de out. 2016.

PEREIRA, T.C.G. Política Nacional de Resíduos Sólidos: nova regulamentação para um velho problema. Direito e Justiça. v.11. n.17, 2011.

PHILIPPI, Arlindo. Sistema de resíduos sólidos: coleta e transporte no meio urbano. 1979. Tese de Doutorado. Universidade de São Paulo. Faculdade de Saúde Pública.

RAMOS, Silma Pacheco. A Lei da Política Nacional de Resíduos Sólidos e a meta de implantação de aterros sanitários no Brasil. In: Âmbito Jurídico, Rio Grande, XVII, n. 121, fev 2014. Disponível em: <http://ambitojuridico.com.br/site/?n link=revista artigos leitura\&artigo $\mathrm{id}=14280 \&$ revista ca

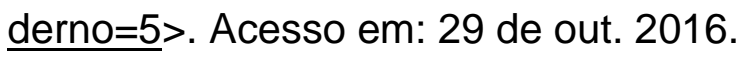

RAUBER, M. E. Apontamentos sobre a Política Nacional de Resíduos Sólidos, instituída pela Lei Federal 12.305, de 02/08/2010. Revista Eletrônica Gestão, Educação e Tecnologia Ambiental. v.4.n.4. 2011. 